\title{
Rahvapäraste taimenimede seosed botaanilise nomenklatuuriga HERBAs
}

\begin{abstract}
Raivo Kalle
Teesid: Historistlik Eesti Rahvameditsiini Botaaniline Andmebaasi (HERBA, http://www.folklore.ee/herba) on koondatud taimede humaanravis kasutamist kajastavaid pärimustekste alates 2006. aastast. Praeguseks on sisestatud arhiivitekstid aastani 1939 ehk oletatavalt veidi alla poole koguhulgast. Taimenimetuste identifitseerimisel tekstides on suuresti aluseks Gustav Vilbaste monograafia Eesti taimenimetused (1993). Kuigi enamiku kogutud eesti taimenimetusi on Gustav Vilbaste identifitseerinud, tuleb pärimusainese läbitöötamisel juurde uusi etnobotaanilisi nimetusi. Artiklis kirjeldatakse HERBAs leiduvate rahvapäraste taimenimetuste seostamist botaanilise nomenklatuuriga ning andmebaasi tekstide ja kirjanduse alusel tuntud rahvapärastele taimenimetustele uute seoste loomist. Andmebaasi tekste saab seostada liikidega kolme kriteeriumi alusel: rahvapärane taimenimetus (Gustav Vilbaste monograafia), tekstis toodud ladinakeelne nimetus ja taimekirjeldus. Artikli üks eesmärk on tutvustada töö käigus taasavastatud taimenimetusi ja seoseid ning anda mõtteainet seni nimeta olnud liikide (nt perekond Gymnosporangium) eestikeelsete nimetuste tekkeks.
\end{abstract}

Märksõnad: arhiivitekstid, etnobotaanika, HERBA, Gustav Vilbaste, rahvameditsiin, rahvapärased taimenimetused

Eestlastel, kui Euroopa ühel vanimal paikkondlikul rahval, on välja kujunenud tihe side kohaliku loodusega, mis muu hulgas väljendub rikkalikus taimenimetuste pärandis. Kirjakeele mõjul on sõnavara küll ühtlustumas, kuid varasemates pärimusallikates on seni säilinud praeguseks juba käibelt kadunud või uue tähenduse saanud taimenimetused.

Gustav Vilbaste (1885-1967), kelle tööd looduskaitses, botaanikas ja ajakirjanduses on raske alahinnata, suutis arvukate põhitööde kõrval hakata koguma rahvapärimust juba 1902. aastast ja jätkas seda oma elupäevade lõpuni (Hiiemäe 2005). Vabatahtlikkuse alusel kogus ta ulatusliku omanimelise käsikirjalise kogu, mida talletatakse Eesti Kirjandusmuuseumi Eesti Rahvaluule Arhiivis. Suuresti sellele kogule tuginedes ning Eesti Rahvaluule Arhiivi teiste käsikirjaliste kogude ja ilmunud kirjanduse põhjal valmis käsikiri Rahvapä- 
raseid taimenimesid Eesti NSV-s (1944-1945). Andmete kontrollimise vajadus osutus ootamatult suureks ja arvukatele vabatahtlikele toimetajatele vaatamata jõuti toimetamisega lõpule mitukümmend aastat pärast koostaja lahkumist. Raamat (Vilbaste 1993) sai nüüdisaegsema nime ja selle põhjal koostati lisaks arvutiandmebaas (Eesti taimenimetuste arvutiregister Vilbaste). Vaatamata Gustav Vilbaste uurimuse põhjalikkusele (midagi samaväärset on üllitanud meie sugulasrahvastest vaid soomlased (Suhonen 1936)) on selgunud, et taimravitekstides esineb rahvapäraseid nimesid, mis selles uurimuses ei kajastu.

Historistliku Eesti Rahvameditsiini Botaanilise Andmebaasi (edaspidi HERBA) rahvapäraste taimenimetuste liigitamise käigus selgus autorile, et andmebaas võiks pakkuda lisa juba trükis avaldatud allikatele, mis rikastaks taimepärandi mõistmise võimalusi. Käesolev artikkel näitabki HERBA kasutamise võimalusi varem tuvastamata rahvapäraste taimenimetuste seostamisel botaanilise nomenklatuuriga ja uute seoste lisamisel.

\section{HERBA}

HERBA loomist on alustatud juba enne Gustav Vilbaste monograafia ilmumist, kuid see tegi läbi mitmeid muundumisi enne kui hakkas 2006. aastast paiknema aadressil http://www.folklore.ee/herba (vt täpsemalt HERBA loomislugu Sõukand 2007b). Viimastel aastatel valmib andmebaas suuresti Eesti Haridus- ja Teadusministeeriumi riikliku programmi "Eesti keel ja rahvuslik mälu" projekti ja Ettevõtluse Arendamise Sihtasutuse toetatud ühekordse projekti "Rahvapärimuse baasil uute ravimtaimede tuvastamise eeluuring" raames ning Eesti Kultuurkapitali ja Hasartmängumaksu Nõukogu toel.

Andmebaasi koondatakse tekstid Eesti Kirjandusmuuseumi Eesti Rahvaluule Arhiivis hoiul olevatest kogudest. Artikli kirjutamise seisuga (märts 2008) sisaldas andmebaas ligi 3600 kollatsioneeritud ja keeleliselt toimetatud teksti, mis pärinevad aastaist 1868-1939. See on ligikaudu kolmandik koguhulgast. Allpool on sisestatud käsikirjaliste kogude loetelu (koos lühendite ja kogumisaastatega):

ALS - Akadeemilise Loomaarstiteadusliku Seltsi rahvameditsiini kogu, 19281934

E - M. J. Eiseni rahvaluulekogu, 1880-1934

EKS - Eesti Kirjameeste Seltsi rahvaluulekogu, 1867-1891

ERA - Eesti Rahvaluule Arhiivi rahvaluulekogu, 1927-1944

ERM - Eesti Rahva Muuseumi rahvaluulekogu, 1915-1925 
E, St K (EVR) - M. J. Eiseni stipendiaatide rahvaluulekogu, 1921-1927

H - J. Hurda rahvaluulekogu, 1860-1906

Tekstid on kopeeritud originaalallikatest (või mikrofilmidelt, kui originaalkäsikirjad ei ole kättesaadavad) ja valitud kahe koos kehtiva kriteeriumi alusel:

1. tekstis peab olema nimetatud inimeste haiguste ravi või profülaktikat, samuti on andmebaasis tekstid, mis puudutavad inimese parasiite, rahvakosmeetikat ja traumasid;

2. tekstis peab olema kajastatud nomenklatuurne või rahvapärane taimenimetus (eeldatavasti Eestis kasvav taim).

Valimisse on lisatud ka tekstid taimedega seotud ravimaagiast ${ }^{\mathbf{1}}$ (nt risti tegemine kasetohule ja haigele kohale panemine); taimeparasiitide või -haiguste põhjustatud iseärasused (tuuleluud, kasepahk); samblad (karusammal); samblikud (kilpsamblik, islandi käokõrv); seened (andmebaasis on praegu esindatud harilik murumuna, punane kärbseseen, harilik tanuseen, tungaltera ja must pässik). Kuigi viimased kuuluvad tänapäeva klassifikatsiooni kohaselt omaette riiki (seeneriigi (Mycetalia) mõiste võeti kasutusele 1939. aastal (Kalamees 2000:8)), on neid traditsiooniliselt peetud rohkem taimedeks (Allen ja Hatfield 2004: 31, Kalamees 2000: 8 jt). Erandina on andmebaasis esindatud ka mõned droogid, mille rahvapärane nimi on sarnanenud kohaliku taime nimetusega ja mille väljajätmine andmebaasist oleks tekitanud hiljem arusaamatusi (nagu näiteks arnika puhul, (vt Sõukand 2007a) või järgmises peatükis toodud isujuure ja niisujuure näited).

\section{Taimenimetuste seosed HERBAs}

Rahvapäraste taimenimetuste ja liikide/perekondade omavaheliseks sidumiseks on HERBAs eraldi liides, mis jääb tavakasutajale kättesaamatuks. Liidese tabeli esimeses lahtris on taime teaduslik liigi või perekonna nimetus (kui taime on võimalik identifitseerida vaid perekonna tasemel), teises rahvapärane nimetus ning kolmes järgnevas reas seose päritolu: kihelkon(na)d; kirjalik allikas(d) - autor ja aastaarv ning kui selle seose kohta on olemas viide ka andmebaasis, siis selle teksti ID (kogu, köite number, lehekülg, pala) (näiteks vt tabel 1). Eestikeelne teaduslik taimenimetus ja ladinakeelne teaduslik taimenimetus on eraldi seostatud teises liideses.

Allikas pärimuses on täidetud tuginedes eeskätt G. Vilbaste monograafiale (Vilbaste 1993) ja/või arvutiregistrile (Vilbaste). ${ }^{2}$ Seal on ära märgitud nimetuse päritolu kihelkonna, maakonna või piirkonna täpsusega. Allikas 
Tabel 1. Herba taimenimetuste seostamisliidese skeem

\begin{tabular}{|l|l|l|l|l|}
\hline $\begin{array}{l}\text { Taime liik / } \\
\text { perekond }\end{array}$ & $\begin{array}{l}\text { Rahvapärane } \\
\text { taimenimetus }\end{array}$ & $\begin{array}{l}\text { Allikas } \\
\text { pärimuses }\end{array}$ & $\begin{array}{l}\text { Allikas } \\
\text { kirjanduses vm }\end{array}$ & $\begin{array}{l}\text { Allikas } \\
\text { HERBAs }\end{array}$ \\
\hline harilik maavits & Maavits & $\begin{array}{l}\text { L.-E., Ha, Jä, } \\
\text { Lä, Vi, Har }\end{array}$ & $\begin{array}{l}\text { KT 1917, Kunder } \\
\text { 1882, Pill 1913 }\end{array}$ & \\
\hline väike hiiresaba & Maavits & Ta & EÜS herb. & \\
\hline harilik maavits & maavitsad & & & $\begin{array}{l}\text { H I 6, 10, } 3, \\
\text { III (28) }\end{array}$ \\
\hline roomav tulikas & maavitsad & Kuu & & \\
\hline
\end{tabular}

kirjanduses on samuti täidetud peamiselt Vilbaste teose toel, kusjuures pistelisel kontrollimisel on selgunud, et andmebaasi usaldusväärsuse suurendamiseks vajaksid allikad ülekontrollimist originaaltekstidest, olgu selleks siis pärimus või kirjandus. Näiteid ebatäpsustest kirjanduse tasandil on leitud juba varem (vt Kalle 2007: 107-108). Esialgu on HERBAs leiduvaid rahvapäraseid taimenimetusi kirjalikest allikatest üle kontrollitud vaid murdosa (Wallner 1929 ja Lääts 1939).

Arstitudeng Jaan Lääts (1909-?) korjas taimravi pärimust ja taimenimetusi, mida ta suuresti kasutas oma raamatu Kodumaa ravimtaimed (muutus väga populaarseks, sellest on välja antud vähemalt kuus kordustrükki, viimane 1993. aastal) jaoks, pikemalt on sellest juttu järgmises peatükis. Antud teosest on pärit mõned näited uutest taimenimedest ja seostest, mis HERBA ravitekstides esinevad:

kurruleht (Vilbaste: puudub) - kortsleht Alchemilla vulgaris (Lääts 1939: 128 )

üheksamehevägi - üheksavägine Verbascum thapsus (Lääts 1939: 109) (Vilbaste: pehme madar),

kassinaeris - harilik altee Althaea officinalis (Lääts 1939: 122) (Vilbaste: ümaralehine kassinaeris) jt.

Proviisor Rudolf August Vallner (1879-1950) kutsus juba 1913. aastal ajalehtedes üleskutsega arstirohtude nimetuste asjus kõiki rohuteadlasi saatma talle rahvarohtude nimetusi. Tema üleskutse avaldasid ajalehed Kiir (2. märts, Vallner 1913a), Tallinna Teataja (4. märts, Vallner 1913b), Päevaleht (24. aprill, Vallner 1913c) ja Olevik (1. mai, Vallner 1913d). Esimese aasta aruandes oktoobris nimetab ta juba 6 informanti ja lisaks ühe autori nime nimetamata 
trükist Maal kasvavad arstirohud; kokku on saadetud 1405 arstirohtude nimetust (Vallner 1913e, Vallner 1913f). Aastate jooksul laienes saatjate hulk: kokku oli korrespondente 29, Vallner ise vaatas läbi kirjalikud allikad (Vallner 1929: 3). Käsiraamat ilmus alles 1929. aastal ja sealt ongi andmebaasi lisatud apteekides müüdavate droogide nimed, mille nimetus kattub rahvapärase taimenimetusega. Näiteks olgu toodud nimetus niisujuur. Väike murdesõnastik annab sellele sünonüümid: miisu-, miisa-, niisajuur (Pall 1989: 28), Vallneril on lisaks neesu- (Vallner 1929: 88), nisu- (Vallner 1929: 90) ja misujuur (Vallner 1929: 81). Vilbaste andmebaasis need nimetused puuduvad. Nimetus niisujuur on tõenäoliselt tõlge droogi saksakeelest nimest - Nieswurz (Ennet 1990: 234). Vallner toob antud nimetuse vasteteks:

roheline niisujuur Radix Hellebori viridis (arvatavasti roheline lumeroos Helleborus viridis), seatubaka juur Radix Hellebori nigri (arvatavasti must lumeroos Helleborus niger),

valge upsujuur Rhizoma Veratri albi (arvatavasti valge upsujuur Veratrum album),

südame-emajuur Gentiana cruciata.

Vaid viimane loetletuist kasvab Eestis. Esimesed kolm on tuntud väga mürgiste taimedena. Need droogid on andmebaasi sattunud vaid selle tõttu, et nende ühisnimetajaks on erinevates variatsioonides niisujuur, millega kutsutakse ka kohalikku liiki südame-emajuurt. Järgnevast tekstinäitest on selgelt aru saada, et tegu on südame-emajuurega, mida korrespondent nimetab ka kalkarijuur (Vilbaste: nimetus puudub), südameemajuur, miisujuur.

Kui on seest veninud.

Kalkarijuur, südameemajuur, miisujuur.

Need pudelisse ajada, sooja vett pääle. On nad ligunenud, siis spiritust pääle valada, nii et paras kange sisse võtta. Aga mitte rohkem korraga kui õige pisikene pitsklaasitäis korraga, seepääle voodisse heita. E 46006 (13) < Tallinn, Nõmme - Jaak Laarmann < Mari Midari (1907).

Teises näites on aga selge sõnaga öeldud, et rohtu on toodud apteegist.

Kui väksel lapsel isu puudund, toodud apteegist isujuurt ( nisujuurt). ERA II 6, 472 (20) < Rapla khk, Kuusiku m - Richard Viidebaum < Jaan Ots, 73 a, Tiiu Ots, 69 a (1928).

Isujuur on Vilbaste järgi harilik kalmus Acorus calamus. Kuna ka Vilbaste ainuke seos pärineb samast kohast (Vilbaste 1993: 127), on ta seose loonud 
tõenäoliselt sama teksti alusel, viidates sellele, et kalmust on kasutatud isuäratajana (samas: 128). Vallneril (1929: 27) on isujuured

südame-emajuur Gentiana cruciata,

kalgani juurikas Rhizoma Galangae (arvatavasti suur kalganirohi Alpinia galanga),

valge upsujuur Rhizoma Veratri albi (arvatavasti valge upsujuur Veratrum album).

Viimased kaks on jällegi apteekides müüdavad droogid. HERBAs on moodustatud taimemärksõna "isujuur(ed)". Viimane näitetekst on liigitatud nii uue märksõna "isujuur(ed)" alla kui ka selle tõttu, et ära on toodud teinegi nimi, ka märksõna "niisujuur" alla.

HERBAs on artikli kirjutamise seisuga lisaks ülaltoodud näidetele kasutatud droogide nimetusi märksõnade saaretõrv, sassaparilla juur, sassaparella ja nabajuur puhul.

Juba Vilbaste monograafias ja arvutiregistris käsitlust leidnud teostele on autor HERBAs lisanud varem kasutamata, eeskätt hilisemaid sekundaarsemaid allikaid (Issako 1989; Kuresoo jt 2001; Tammeorg jt 1973). Mõned näited:

krossilehed - aed-salvei Salvia officinalis (Tammeorg jt 1973: 205) (Vilbaste: külmamailane),

upinhain - teekummel Chamomilla recutita (Tammeorg jt 1973: 76) (Vilbaste:

lõhnav kummel, mägiristik, valge ristik),

kasekäsn ${ }^{3}$ - must pässik Inonotus obliquus (Tammeorg jt 1973: 188),

suur kobruleht - katkujuur Petasites hybridus ${ }^{4}$ (Kuresoo jt 2001: 96) (Vil-

baste: - villtakjas Arctium tomentosum),

maakõrvad - kilpsamblik Peltigera (Kuresoo jt 2001: 160),

tuuleluud - kaseluudik Taphrina betulina (Kuresoo jt 2001: 164). ${ }^{5}$

Esialgu on kontrollitud algallikatest lisanduvate uute seoste hulk protsentuaalselt väike, kuid kui arvestada nende allikate lisamist juba andmebaasis olemas olnud määratud liikidele, on protsent oluliselt suurem. Näiteks Vallneri (1929) põhjal on andmebaasis seoseid kokku 130, nendest ligi 40 lisandus kontrollimisel. Võib kindlalt väita, et seoste kontrollimine tõstab andmebaasi usaldusväärsust. Sellepärast tuleks vastavalt võimalustele jätkata Gustav Vilbaste algallikateks olnud teoste kontrollimist ja hilisemate kirjalike allikate uurimist.

Kolmas allikate tulp on tekkinud andmebaasi alles pärast märkimisväärse osa tekstide liigitamist, kui selgus vajadus viidata ka andmebaasis endas kajastatud tekstidele. Edasine arutelu keskendubki andmebaasis sisalduvate tekstide põhjal tekkivatele uutele seostele rahvapäraste taimenimetuste ja taimeliikide/perekondade vahel. 


\section{HERBA taimenimetuste seostajana}

Tavaliselt on seni HERBAs sisalduvates pärimustekstides nimetatud taime üks rahvapärane nimetus. Paljudes tekstides on lisaks taime nimetusele toodud ära ka selle kasvukoht ja/või välimus, mis lihtsustab taime täpsemat määramist, sest paljud populaarsed taimenimetused viitavad mitmele väga erineva välimusega taimele. Mõne (eeskätt meditsiinilise või loodusteadusliku taustaga) korrespondendi tekstid sisaldavad lisaks rahvapärasele taimenimetusele ka ladinakeelset nimetust, millesse tuleks suhtuda ettevaatlikult ja arvestada korrespondendi tausta.

\section{Rahvapärane taimenimetus ja ladinakeelne nimi}

Andmebaasi pärliks (esmapilgul) ja esimeseks suuremamahuliseks ladinakeelsete nimevastete allikaks võib lugeda proviisor Hans Jako (Jaaku) saadetud tekste Hurda kogus. Tekstide väärtus seisneb selles, et neis on kirjeldatud mitte ainult taime kasutamist vaid on lisatud ladinakeelne nimetus ja taime erinevad rahvapärased nimetused. See tähendab, et ühte teksti on pandud kaks teavet: kuidas taime kasutatakse ja kuidas teda ümbruskonnas kutsutakse. Kahjuks on teadmata Jako saadetud rahvapäraste taimenimetuste päritolu: töötades Tartus, kogus ta nähtavasti informatsiooni oma saadetiste jaoks apteegikülastajatelt.

Ühe saadetise kümne kasutusega on Jako saatnud juba Jakob Hurda esimese üleskutse peale 1888. aastal. Pooled neist on kahjuks droogide nimed (HERBAsse sobis neist 7), mida Eestis looduslikult leida ei ole, samas hariliku palderjani Valeriana officinalis puhul on lisatud koguni 14 rahvapärast nime. Teise üleskutse peale 1894. aastal on Hans Jako saatnud juba 36 kasutust, kõik taimed kohalikust taimestikust (näiteks harilikul nurmenukul on toodud neli nimetust). Siiski esineb siin mitmeid küsitavusi. Näiteks:

Karukäpad, harakalilled, karvalilled (Anemone pulsatilla). Pruugitakse luu-ja peavalu vastu. H I 6, 9 (4) < Tartu - Hans Jako (Jaaku) (1894).

Võib arvata, et juttu on harilikust karukellast Pulsatilla vulgaris (sünonüüm Anemone pulsatilla), mille leidumine Eesti looduses on herbaarselt tõendamata (olevat kasvanud Narva jõe suudme lähedal), harva kasvatatakse seda kultuurtaimena (Tallinna Botaanikaaias alates 1960. aastast) (Kukk 1999: 209). Antud teksti põhjal võib oletada, et Jako kasutas Wiedemanni ja Weberi taimemäärajat, milles Pulsatilla vulgaris kirjelduse juures on antud ka eestikeelsed nimetused karu kepad (kellad), karwa lilled, haraka niin ning taim on 
märgitud kodumaiseks, teda leidub Kuressaares ja Tartus (Wiedemann \& Weber 1852: 293). ${ }^{6}$ Aas-karukellal Pulsatilla pratensis on taimemäärajas samad nimetused (Wiedemann \& Weber 1852: 294). Sama Jako teksti on aluseks võtnud ka Gustav Vilbaste ja määranud selle taime hoopis aas-karukellaks Pulsatilla pratensis (Vilbaste 1993: 514, harilik karukell Vilbaste raamatus puudub).

Järgmise, palju ulatuslikuma ladinakeelsete taimenimetustega varustatud kogumi on talletanud arst Mihkel Ostrov (1863-1940). Mihkel Ostrov sai innustust taimepärimuse korjamiseks tudengipõlves, mil ta koos tulevase folkloristi ja poliitiku Oskar Kallasega (1868-1946) käis Virumaal ja Läänemaal Jakob Hurda lähetatud stipendiaadina peamiselt laule korjamas. Hiljem on ta märkinud: vanu laule korjates leidsin igal pool, et rahva seas rohutarkasid weel kaunis rohkesti on, kes nurmelt ja niidult kõiksugu taimesid korjavad ning neid siis mitmesuguste hädade wastu tarvitawad (Ostrov 1891a, b, c). 1891. aasta aprillis avaldas ta Postimehes (6. aprill, Ostrov 1891a), Olevikus (8. aprill, Ostrov 1891b) ja Sakalas (26. aprill, Ostrov 1891c) palved üleskutsetega Üleüldisele Eesti arstirohtude korjamisele, kus ta väga täpselt kirjeldas, kuidas taimi korjata ja kuivatada ning herbaarlehele märkida rahvapärane nimi ja täpne kasutus. Tagasiside korjamisest avaldas ta juba juulis Olevikus (1. juuli, Ostrov 1891d) ja Postimehes (2. juuli, Ostrov 1891e) ning teise aruande oktoobris ajalehes Olevik (21. oktoober, Ostrov 1891f) ja Postimehes (29. oktoober, Ostrov 1891g). Arvatavasti oli taimede kuivatamine ja hiljem puukastides saatmine ebamugav, sest esimese aasta üleskutsele vastas ainult 13 korrespondenti, kellest mõni läkitas kaks saadetist, kokku 17 saadetist 192 taime ja 53 punkti arstimiskommetega. 1892. aasta üleskutsete peale aprillis Postimehes (25. aprill, Ostrov 1892a), Olevikus (27. aprill, Ostrov 1892b) ja Sakalas (29. aprill, Ostrov 1892c) andis ta ainult ühe aruande novembris Postimehes (7. november, Ostrov 1892d) ja Olevikus (16. november, Ostrov 1892e), kus on ära toodud nelja korrespondendi nimed, kes saatnud teavet kokku 48 taime kohta. Kolmandale üleskutsele 1893. aasta 26. aprilli Olevikus (Ostrov 1893) aruannet ei järgnenud. Korrespondentide saadetud tekstid on Ostrov ümber kirjutanud, säilitades paikkondlikud taimenimetused koos täheerinevustega (nt kummel, kamelid, kummelid jt). Võib oletada, et Mihkel Ostrov tundis taimi hästi, sest ta on lisanud lisaks täpsele ladinakeelsele nimele ka sugukonna nime. Herbas on praegu Ostrovi kogust 129 teksti 1891. aastast ning 15 teksti 1892. aastast, kõik pärit Eesti Kirjameeste Seltsi kogust. Herbas hõlmab Mihkel Ostrovi kogu 14 Lõuna- ja Ida-Eesti kihelkonda (aruannetes on ta nimetanud samuti 14, kusjuures kaks nimekirja erinevad üksteisest nelja kihelkonna võrra) ning lisaks on ühe teate jäädvustanud ta ise Läänemaalt (vt Levikukaart 1). 


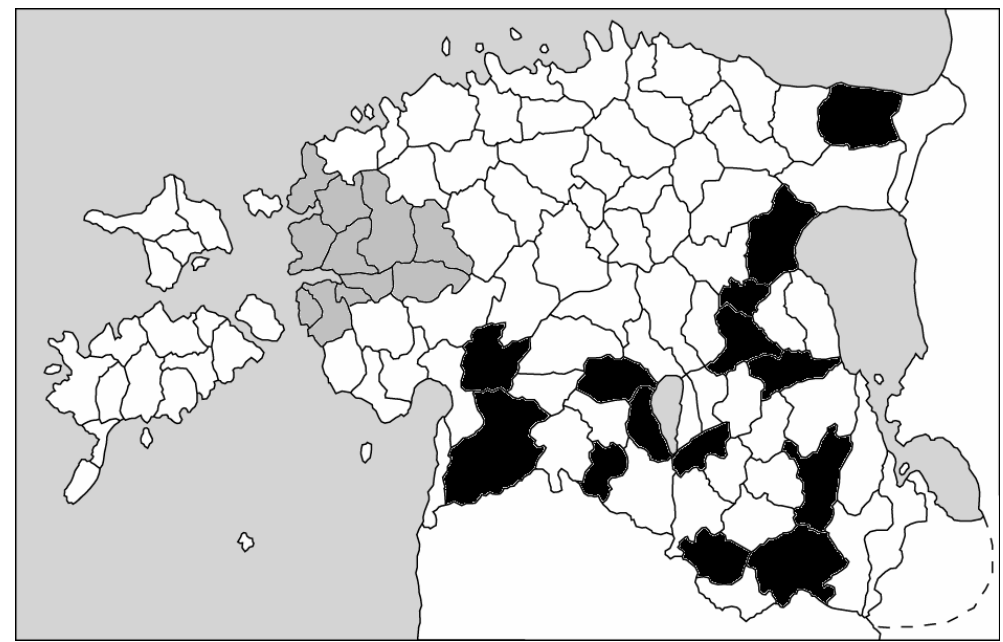

Levikukaart 1. Kihelkonnad, kust pärinevad Mihkel Ostrovile saadetud taimravialased pärimustekstid. Helehalliga on märgitud Läänemaa, kust pärineb üks teade.

1937. aastal lähetas ka Vilbaste kaastööliste hulka kuulunud Albu vallast pärit kooliõpetaja ja looduseuurija Julius Lunts (1902-1941) ERA kogusse JärvaMadiselt ja Amblast 63 taimekasutusega saadetise. Sellest suurema osa moodustavad rahvapärased taimenimetused ladinakeelsete täpsustustega.

1938. aastal on samuti ERA-sse korraga 203 taimekasutust saatnud Jaan Lääts, kes on need kogunud peamiselt Põltsamaa ja Kolga-Jaani vallast ning kaks teksti Karulast, samuti enamusel ladinakeelsed nimed. Võib arvata, et nendest kolmest kihelkonnast kogutud pärimust (või vähemalt osa sellest) on ta kasutanud ka oma raamatu Kodumaa ravimtaimed (Lääts 1939, V väljaanne) koostamisel, seda näitavad ühised lokaalsed rahvapärased taimenimetused tema kogus ja raamatus (raamatus näidatud juba üldlevinutena).

Lisaks on andmebaasis veel rida korrespondente, kes on saatnud üle kahe taimekasutuse teksti, mis on varustatud ladinakeelsete nimetustega:

1892. aastal 11 teksti meditsiinitudeng Hans Lohk (25-st),

Aastail 1940-1942 viis teksti Aadu Toomessalu (15-st),

1931. aastal viis teksti Albert Paabo (30-st),

1921. aastal viis teksti Sigfried Lind (26-st),

1903. aastal neli teksti Jakob Hurt Setumaalt (10-st),

1920. aastal kolm teksti Aleksander Tiitsmann (27-st),

1897. aastal kolm teksti Ernst Tetsman (8-st). 
Gustav Vilbaste on kasutanud Ostrovi, Jako, Läätse ja Luntsi saadetud/kogutud seoseid, kuid kontrollimise käigus selgus, et valikuliselt. Näiteks Mihkel Ostrovi kogust tuli juurde üle 15 seose, mida Vilbastel ei olnud. Nähtavasti kasutas Gustav Vilbaste oma monograafia ettevalmistamisel mitte originaalkäsikirju, vaid olemasolevaid (nt rahvabotaanika vms) kartoteeke. Et näiteks rahvabotaanika kartoteeki hakati täiendama alles pärast tema surma (1967. aastal), võis ta ammutada informatsiooni lünklikult täidetud kartoteegist. ${ }^{7}$

\section{Küsimusi tekitavad ladinakeelsed nimetused ja dubletid}

Alati ei saa kõikide korrespondentide ladinakeelseid nimetusi seostamisel tingimusteta aluseks võtta. Heaks näiteks on metsavaht, põllumees ja ajalehtede kirjasaatja Jaak Sõggel (1871-1963), kelle aastatel 1892-1938 (46 aastat) saadetud taimravipärimust puudutavaid tekste on HERBAs kokku 85, pärit Halliste ja Saarde kihelkonnast, vaid kaks kasutust on jäädvustatud Paistust. Sõggeli (kuid mitte ainult tema) eripäraks on see, et ta on paralleelselt saatnud sama informatsiooniga tekste nii Hurda kui ka Eiseni ja hiljem ERA kogudesse. Samas ladinakeelse nime on ta lisanud ainult üksikutele, mis samuti korduvad erinevates kogudes. Järgnevalt analüüsime mõnda neist.

1893. aastal on Jaak Sõggel saatnud nii Hurdale kui Eisenile kirjutised, kus ristrabanduserohi nime kõrval seisab Thalictrum flavum. Ta on ka kogumiskoha märkinud igal saadetisel erinevalt: esineb nii kihelkonna, valla kui küla täpsusega tekste.

On inimene rabatud, siis keeda ristrabantuse rohi (Thalictrum flavum) paja sees ja anna haigele sisse; haigel tuleb aga sissevõtmise ajal hing kinni hoida ja parem käsi üles taeva poole. Küll ta siis terveks saab. H III 13, 657 (7) < Halliste khk - Jaak Sõggel (1893).

On inimene rabatud, siis tuleb ristrabanduse rohi (Thalictrum flavum) paja sees keeta ja haigele sisse anda; haige peab aga sissevõtmise juures hinge kinni hoidma, nii et ei hinga. Rabat haigused: tuulest rabatud, ilmast rabatud, õhust rabatud jne. H III 19, 326 (7) < Halliste khk, Kaarli k - Jaak Sõggel (1894).

On inimene ära rabatud, siis keeda ristrabanduserohi (thalictrum flavum) ummusses paja sees ja anna seda siis haigele iga päev üheksa korda sisse. Haige peab sisse võttes hinge kinni pidama ja suu vastu päeva hoidma. Tähentus. Rabathaigused, tuulest rabat, ilmast rabat, õhust rabat jne. E 3897 (27) < Halliste khk, Kaarli v, Saaremetsa k < Paistu khk - Jaak Sõggel (1893). 
Jakob Hurt jagas ajalehtedes oma korrespondentidele tunnustust, sh ka Sõgelile 11 arstimise eest sõnadega Kõigiti kallis korjandus... Täname kõigest südamest ja rõõmustame, et suurem kiri tuleb jälle ( Hurt 1893). Sellest sai Jaak Sõggel arvatavasti innustust ja ta saatis Hurdale sama sisuga teate uuesti 1894. aastal. Ehk olid need korduvad arstimistekstid põhjuseks, miks Hurt julgustavalt teda teisendeid saatma kutsus (Hurt 1894). Gustav Vilbaste arvutiregistrist leiame samuti need seosed allikate hulgast.

Järgmine Eisenile saadetud taimekasutus kirjeldab sööjarohu (harilik piimalill Euphorbia helioscopia) kasutamist:

Sööja rohi (Euphorbia helioscopia). Kui sööja inimesel selja sees ehk ka mujal on, siis tuleb sööjarohtu iga hommiku korjata, üheksama hommiku jagu kokku panna ja ära keeta. Pärast tuleb see ärakeedetud vedelik sööja kohale peale võida. Enne võidumist tuleb aga sõrmega haige koha pääle seitse viienurgalist risti tõmmata. Küll sööja sedamaid kaduma saab. E 3899 (39) < Halliste khk, Kaarli v, Saaremetsa k < Paistu khk Jaak Sõggel (1893).

Ülekäiaheina vasteks on Sõggel pannud hariliku palderjani Valeriana officinalis, Vilbaste arvutiregistrist see nimetus puudub, nagu ka eelmine, kuid sarnase nimetuse (ülekäijarohi) juures on ohtralt kirjanduslikke ja pärimuslikke allikaid.

Ülekäiahein (valeriana officinalis) on rohuks rampide vastu. Leent võib keedetult sisse võtta, nii kui ka kuivalt haisutada. Kui rambid veest ujuden on saanud, siis tuleb sinna kohta kusalt jõest välja sai tultud vanahõbe maha kaabitsema, ikka nii, et tuult kaabitsedes vanahõbele pääle ei puudu. E 3898/9 (38) < Halliste khk, Kaarli v, Saaremetsa k < Paistu khk Jaak Sõggel (1893).

Aasta hiljem (1894) on Sõggel saatnud sarnase sisuga teksti, samast kihelkonnast, nüüd juba Hurda kogusse: "ülekäijahein” on seekord vasteks saanud Euphoriana officinalis - nimetus on suure tõenäosusega vigaselt kirjutatud ladina keel.

Ülekäijahein (Euphoriana officinalis) on rohi rambide vastu. Leent võib keedetult sisse võtta, nii kui ka kuivatult haisutada. H III 19, 328 (14)< Halliste khk, Kaarli k - Jaak Sõggel (1894).

Võib muidugi oletada, et korrespondent on teadnud täpselt üksikuid ladinakeelseid taimenimetusi ja Euphoriana officinalis on tekkinud kahe tuntud ladinakeelse nimetuse tahtlikul/tahtmatul liitmisel. 
Küsitavusi taimede tuvastamisel leidub ka üldjoontes usaldusväärsete korrespondentide saadetistes, nagu näiteks:

[Labiatae] Mentha crispa

Münt. Rohi teeks keeta on hää köha ja külmetamise vastu. EKS c, $64(3)<$ Äksi khk - Mihkel Ostrov (1891).

Vilbaste arvutiregistris on münt seotud järgmiste liikidega:

vesimünt Mentha aquatica,

põldmünt Mentha arvensis,

käharmünt Mentha crispa,

harilik pune Origanum vulgare,

harilik käbihein Prunella vulgaris.

Nimetust käharmünt on esmakordselt maininud Wallner (1929: 61) ja kokku on Vilbaste andmebaasis 20 erineva nimekujuga käharmünti, mille ladinakeelseks vasteks on Mentha crispa. Eestikeelsete taimenimede andmebaasis (http:/ /www.ut.ee/taimenimed/) puudub nimi käharmünt. Eesti NSV floora V köide annab selle nime osas selgust: nimelt vanemal ajal kasvatati rohkem, kaasajal aga harva kultuuris, peamiselt [vesimündi Mentha aquatica] käharalehelist teisendit, mis sisaldab rohkem ja väärtuslikumat eeterlikku õli kui põhiteisend (Eilart jt 1973: 194). Samas on selle nime all mõeldud nähtavasti ka teiste mündiliikide sisselõikunud ning laineliste lehtedega kultuurteisendeid (Eilart jt 1973: 202). Seega on HERBAs loodud uus seos, kus rahvapärase taimenimetuse vasteks on perekond münt Mentha ja allikaks kõne all olnud tekst.

\section{Osaliselt seostatud rahvapärane taimenimetus, millele on lisatud taime kirjeldus ja kasvukoht}

Raskem on tuvastada taime tekstides, kus puudub ladinakeelne nimetus ja milles toodud rahvapäraseid taimenimetusi ei ole keegi eelnevalt sidunud liigi või perekonnanimega. Üks nende tekstide liigitamise moodus on tuletada neis kirjeldatud taim sarnaste juba seostatud taimenimetuste ja taimekirjelduse ja/või kasvukoha abil.

Heaks sellise seostamise näiteks on kolm Ernst Grünbergi ERMi kogule saadetud taimekasutust:

Kui kuuriided liiga jooksma hakkavad, siis joodaks kukekannusseteed, mille joomise läbi kuuriiete jooks harilikuks muutub. Kukekannussed ehk rukkisinililled kasvavad rukki- kui ka mujal põldudel. ERM 6a, $30<$ Kursi khk, Puurmanni v, Pikknurme k - E. Grünberg < Leena Nigul, 63 a (1921). 
Kuuriided ja millega arstitaks.

Ka on keedetud ja joodud kukekannuse ehk kulliküine teed - mis muud pole kui harilikud rukkisinililled. Kukekannused (ehk rukkililled) olla mõjusaks kaotuseks, kui kuuriided liiga jooksevad. Kukekannused kasvada rukkis. Ja joodaks teena. Ja kuuriiete jooks muutunud hariliseks. ERM 6, 10 b < Kursi khk, Puurmanni - E. Grünberg (1921).

Kui kuuriided liiga jooksma hakkavad, siis juua kulliküineteed (rukkisinised), siis kuupuna jooks harilikuks. ERM 6a, 24 < Kursi khk, Puurmanni v, Tammiku k - E. Grünberg < Kadri Kabel, 76 a (1921).

Kõik tekstid pärinevad ühelt kogujalt ja ühest kihelkonnast, kuid erinevatest küladest. Võib oletada, et kirjeldatud on ühe taime kasutamist. Taime on nimetatud kukekannused, rukkisinililled, kullikü̈̈ned, rukkililled ja rukkisinised. Mida annab meile nende nimetuste vastetena Vilbaste arvutiregister?

Rukkisinised on rukkilill Centaurea cyanus,

kullikü̈̈ned võivad aga olla kas

harilik kurekell Aquilegia vulgaris, harilik saialill Calendula officinalis, harilik kurekael Erodium cicutarium, aas-kurereha Geranium pratense, haisev kurereha Geranium robertianum või harilik nõiahammas Lotus corniculatus;

kukekannus võib olla kas

harilik kassikäpp Antennaria dioica, põld-varesjalg Consolida regalis, harilik käokannus Linaria vulgaris, harilik nõiahammas Lotus corniculatus, harilik nurmenukk Primula veris;

rukkililled võivad olla kas

harilik äiakas Agrostemma githago, põld-varesjalg Consolida regalis või rukkilill Centaurea cyanus.

Ühist nimetajat neil rahvapärastel taimenimetustel ei ole. Tuletades taime kasvukohta rukki- kui ka mujal põldudel ja õie välimuse (sinine ja meenutab küünt või kannust) järgi, tundub loetelust vasteks sobivat põld-varesjalg, mis 


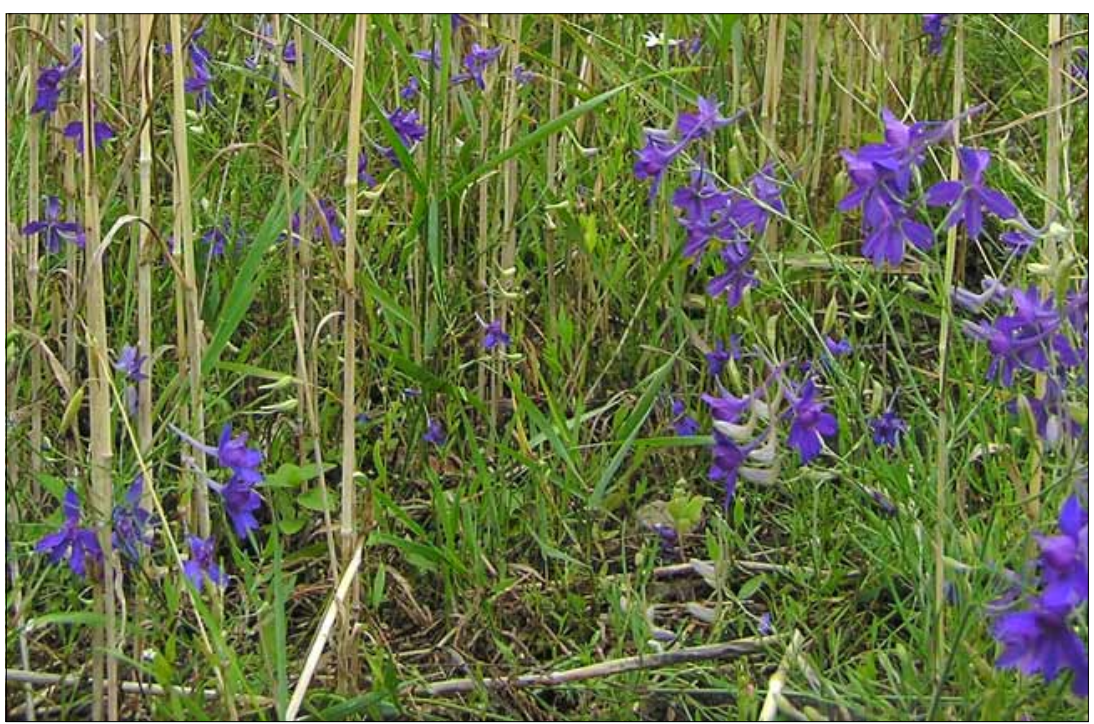

Foto 1. Põld-varesjalale on iseloomulikud küüne-või kannusekujulised õied, millest on tulnud ka rahvapärased nimetused kulliküüned, kukekannused jt. Kasvukoha ja õie värvuse järgi on teda nimetatud ka rukkisinililleks, rukkisiniseks jne. Toomas Kuke foto.

vastab nendele tingimustele. Analüüsi ja kõrvutuste tulemusena on HERBA täienenud mitme seose võrra: rukkisinised ja kulliküüned on juurde saanud seose põld-varesjalaga ning lisandunud on uus rahvapärane taimenimetus rukkisinililled, mille ainuvasteks on põld-varesjalg; allikaks on kolm eespool toodud teksti HERBAst.

\section{Seostamatu rahvapärane taimenimetus, kuid on kirjeldatud taime välimus ja kasvukoht}

Pärimustekstide liigitamisel tekib märkimisväärselt ka olukordi, kus taimenimetusel puudub üldse seostatus botaanilise liigiga. Ühesuguse taimenimetuse ja kirjeldusega tekstid on töö käigus välja korjatud ja määramiseks piisava hulga olemasolul on need koondatud ühise nimetuse alla. Enamasti ühe kirjelduse põhjal veel liigitada ei saa. Peab vaatama sarnastes kirjeldustes toodud kasvukohta, taime välimust ja teisi parameetreid. Allpool on mõned näited:

"Vähälaka juurõ" otsitakse kevadel kohe pääle lume sulamist õitsemise ajal. Taimel on sinikad või roosakad õied, mis umbes 1/2 tolli pikkuse varre otsas. Juured kuivatakse ja keedetakse saarelehtiga koos. Saadud teed antakse 2 korda päevas juua. Rohi võtab alati valud ära. ERM 17, 4 (8) < Põlva khk, Mammaste k - Paul Reim < Liisa Moistu (1920). 
Tiiskuse vastu vähalakad - maarohud.

Kasvab vana haava-sarapuumõtsa all, madalas kohas, tuleb maa seestsõrmejämedune. Kui maa seest tuleb, siis ju õitseb, ühe päeva pärast kaub maa ala, käänab pea alla kõveras, kaub - oitseb jälle maa all. Õilmed nagu hiirehernel. Maa all juured paar jalga sügaval - palju. Keeta ummuksen [---] mõõdutäis juuri. E 29512 (4) < Viljandi khk - Anton Suurkask (1896).

Vaivaja - lapsel (inimesel) ajab valu jalgade sisse ja nimme sisse. Vaivajarohud -, õits. enne jüripäeva - nagu hiireherne ôilmed, all nagu munad marjad (vähjalakk). Valgemad jõeveeres. Keedetakse, antakse lapsele juua, sagu köödetakse kõtu peale. E 29513 (5a) < Viljandi khk - Anton Suurkask (1896).

Võib öelda, et kirjeldatakse ühte taime: ühine on koondnimetus vähilakk; sarnane kasvukoht ja välimus. Kui püüda läheneda taimele vaivajarohu nimetuse kaudu, võib sattuda eksiteele: Gustav Vilbaste arvutiregistri kohaselt on vaivajarohi südame-emajuur Gentiana cruciata ja vähilakk puudub. Südameemajuur kasvab kuivadel niitudel, paepealsetel (Reier 2007: 219). Järelikult ei saa olla tegu südame-emajuurega. Mõeldes spetsiifilisele kasvukohale just sarapuumetsa all ja õitsemisele - õitseb jälle maa all - ning teistele iseärasustele, saab selleks taimeks olla ainult mailaseliste sugukonda kuuluv enamasti sarapuu ja lepa juurtel parasiteeriv harilik käopäkk Lathraea squamaria, millel puudub klorofüll (Reier 2007: 242). Oluline on asjaolu, et taim meenutab oma punase lihaka ühele poole kaldu oleva õieraoga vähilakka.

Analüüsi tulemusena on harilik käopäkk lisatud andmebaasi rahvapärase taimenimetuse vaivajarohi senise seose (südame-emajuur) juurde ning ainsa seosena rahvapäraste taimenimetuste vähalakad, vähjalakk ja vähälaka juurõ juurde. Vähilaka teema võiks sellega ammendatuks lugeda, kuid vaivajarohu analüüsi tuleb jätkata. Nimelt leidub seda nimetust peale ülaltoodud näidete veel kahes:

Vaivajarohu juured olla jooksjahaiguse vastu head. H II 32, 631 (100)< Räpina khk - Joosep Poolakess (1889).

Vaivajarohi olevat jooksjahaiguse vastu hea. E 29574 (94) < Viljandi khk - Anton Suurkask (1896).

Nii 1889. aastal saadetud Joosep Poolakesse Jakob Hurdale saadetud 10 taimekasutust kui ka Anton Suurkase 1896. aastal Eisenile saadetud kirjutised on sisuliselt identsed. ${ }^{8}$ Gustav Vilbaste monograafiast aga selgub, et vaivajarohu määramine südame-emajuureks põhineb just Joosep Poolakesse konkreetsel 
tekstil (Vilbaste 1993: 334). Südame-emajuur kasvab harva Lääne- ja Põhja Eestis. Leiukohtade hulk on viimastel aastakümnetel vähenenud (Kukk \& Kull 2005: 213). Tekib kahtlus kas ka Poolakesse tekstis ei mõelda harilikku käopäkka, sest sobivaid kasvukohti südame-emajuurel Räpina kihelkonnas peaaegu pole ja kogu Lõuna-Eestis on leida ainult 3 (4) usaldusväärset leiukohta (Kukk \& Kull 2005: 213). Käopäkk on levinud hajusalt üle Eesti (Kukk \& Kull 2005: 334), pealegi torkab varakevadel õitsev käopäkk kohe silma - nii võis taim selle eripära tõttu kasutamist leida laiemalt. Sellele hüpoteesile kinnituse leidmiseks vajaks Gustav Vilbaste monograafia aluseks olev kogu põhjalikumat analüüsi just taimegeograafiat silmas pidades.

\section{Kitsama eriala spetsialistide abil tuletatud seosed}

Et andmebaasi on lisatud ka ravitekstid, milledes kirjeldatakse taime, mille kuju on parasiitide mõjul silmanähtavalt muutunud või omaette viljakeha peremeestaimel, siis nende vasted on andmebaasis saadud ainult tuletades. Näiteks võiks tuua nimetuse "kadakarasv", mida esineb seni neljas kasutuse kirjelduses.

Kõrva arstiti ka kadakarasvaga. Kevadel ilmub kadakate okstele kollane rasvataoline või sülditaoline ollus. See aeti lusika sees kuumaks, muidugi ikka nii, et ei põletanud, ja kasteti puhas linane tropp sinna sisse ja pandi kõrva, kui kõrvad haiged olid. ERA II 288, 184 (6) < Tallinn - Eduard Kriitmäe (1940).

Antud seene tuvastamisel andis õige suuna mükoloog Kuulo Kalamees (s 1934), kes arvas, et tegu on roosteseene kevadeoslaga. Roosteseente perekond Gymnosporangium on Eestis esindatud nelja liigiga ja nendest kaks parasiteerivad harilikul kadakal, tekitades näsaroostet (Kask 2000: 133). Etnoloog Aivar Jürgenson (s 1969) märgib, et antud perekonna liike on rahvauskumuses kutsutud pilvetükkideks (Jürgenson 2005: 254). Kadakarasva pole Aivar Jürgenson oma raamatus maininud, küll aga HERBAski sees olevat kadaga seene raviomadusi. Andmebaasis on kõik antud tekstid koondatud kadakarasva nimetuse alla ja seoseks on perekonnatäpsusega määratud Gymnosporangium, mida autor nimetas eesti keeles kadaka roosteseeneks, sest ametlik eestikeelne nimetus seenel puudub. See näide illustreerib andmebaasi võimalikke lisarakendusi: milleks panna nimetus kunstlikult, kui võiks võtta ametlikult käibele rahvapärase nimetuse kadakarasv?

Andmebaasi tegemisel on jooksvalt küsitud nõu ka botaanik Toomas Kukelt. Näiteks võib tuua ühe teksti, mille puhul ta aitas määrata seal nimetatud taime: 
Roosinaerid (Malvae silvestres) tarvitakse keedisena (sisse võtta) jooksja vastu. ERM 168, 14 (20) < Tõstamaa khk < Audru khk < Mihkli khk Sigfried Lind (1921).

Roosinaerid Vilbaste arvutiregistris puudub. Arvatavasti on tegu perekonnas kassinaeris Malva esindatud liigiga, mida pole olemasolevate andmete alusel võimalik liigi täpsusega eristada.

\section{Kokkuvõtteks}

Uute seoste loomisel eesti rahvapäraste taimenimetuste ja botaaniliste liikide/perekondade vahel on vaja teada võimalikult palju taime välimusest, kasvukohast, levikust, nimetustest ja kasutustest. Artiklis on analüüsitud vaid mõnda probleemile lähenemise viisi, kuid see vähenegi näitab, kui oluline on arvestada kõigi võimaluste ja andmemahtudega, mis on andmebaasiga loodud. Kuigi HERBA autorite esialgne ülesanne oli koondada sellesse taimravi tekstid ja süstematiseerida neid võimalikult arusaadavate ja tõepäraste kriteeriumite alusel, on sellest välja kasvamas mitmekülgne, paljude erialade esindajatele (folkloristid, arstid, proviisorid, botaanikud, inimgeograafid jm) huvi pakkuda võiv multifunktsionaalne andmebaas. Võib oletada, et HERBA lisaväärtused suurenevad proportsionaalselt andmemahu (liigitatud tekstide, lisatud taimeseoste) kasvuga, seega on andmebaasi rakenduse seisukohalt oluline jätkata andmebaasi täiendamist ka HERBA enda baasil tekkinud seostega.

Artikkel on valminud Eesti Vabariigi Haridus- ja Teadusministeeriumi riikliku programmi "Eesti keel ja rahvuslik mälu” raames.

Autor tänab oma magistritöö juhendajat Toomas Kukke ning kahte anonü̈̈mset retsensenti artikli algversiooni paranduste eest, Rein Saukast korrespondentide kohta käiva biograafilise teabe eest ja Kalevi Kulli kahe olulise allikaviite eest.

\section{Kommentaarid}

${ }^{1}$ Eesti tunnustatud etnograaf, ajaloodoktor Ants Viires (s 1918) leiab ravimaagia kasutamise kohta taimravis, et puude ja põõsastega nagu üldse taimedega seoses on ravimaagia siiski teisejärguline, sest nende puhul on enamasti tegemist tõeliste "rohtudega", mille mõju inimorganismile oli kogemuste kaudu tundma õpitud (2000: 54).

${ }^{2}$ Arvutiandmebaasi on mugavam kasutada, sest seal saab seoseid otsida lähtudes rahvapärasest taimenimetusest - raamatus see võimalus puudub. Paralleelselt on 
kasutatud ka raamatut, millest on lisatud andmebaasist puuduvaid liike (nt Filipendula vulgaris angerpist jt).

${ }^{3}$ Gustav Vilbase on oma teostes kajastanud vaid soontaimi, seepärast on loomulik, et seosed kõigi teiste andmebaasi kirjete osas pärinevad teistest allikatest.

4 Tihti tulevad sellised seosed välja pärast seda, kui tekstide võrdlemisel tekib küsitavusi. Konkreetne probleem kerkis esile seoses sellega, et üks ja sama korrespondent, pärastine misjonär Hendrik Tutar (1872-1946) saatis kaks teksti, millest ühes ta kirjeldas ja ka nimetas villtakjat: Üks suur lai putke moodi kasv, kutsutakse takjas, kellel ka niisugused nupud külles ning nuppude külles okkad. Neist juurtest tehakse sügelisesalvi. H IV 1, 558 (15) < Jõelähtme khk, Maardu v, Kure k - Hindrek Tutar (1889). Teises kirjeldas ta teist taime, mis oli Vilbaste andmebaasi alusel seostatud samuti villtakjaga: Ka kasvab aia äärtes ja teede peal ning kallastes suured lehed kobrulehed, mis rahvas jooksjahaiguse vasta tarvitavad ja haige koha peale siuvad. H IV 1, 554 (5) < Jõelähtme khk, Maardu v, Kure k - Hindrek Tutar (1889). Katkujuur kasvabki kalda ääres, nõlvadel, parkides, asulate ümber (Kukk 2007: 281) ning on ebatõenäoline, et üks ja sama korrespondent kirjeldab ühte taime niivõrd erinevalt ja rõhutab eraldi, et tegemist on suurte lehtedega. Ka Kuresoo jt (2001: 96) nimetavad katkujuurt suur kobruleht. Et katkujuure rahvapäraseid nimesid pole sisuliselt kogutud (Kalle 2007: 122), on iga uus viide kasuks.

${ }^{5}$ Andmebaasi on lisatud märksõna tuuleluud vasteks lisaks ka perekond luudik Taphrina, mille viiteks on HERBA.

6 Sarnaste liikide määramine on isegi määrajaga harrastajale raske. Ei saa välistada, et ta mõtleski harilikku karukella.

7 Rahvabotaanika kartoteeki kopeeriti aastatel 1967-1970 Aime Lindre ja Tartu üliõpilaste looduskaitseringi abiga poole võrra uusi tekste, välja jäi RKM-i lõpuosa materjal (Korb 1990: 120).

8 Anton Suurkask küsis 1896. aastal Lõuna-ja Kagu-Eesti rahvaluule ekspeditsiooni rahastust muuhulgas ka Eisenilt, kellele ta hiljem kogutud materjali saatis (Saukas 2005: 72). Lisaks enda korjatud pärimusele on tema valdusse kuidagi sattunud Joosep Poolakesse mustandkäsikirjad, mida ta nähtavasti osaliselt oma käega ümber kirjutas (Saukas 2005: 73) ja nagu selgub, pole ta ravitekste ümber kirjutades kas käekirjast aru saanud või on ta Poolakesse tekste omalt poolt kergelt modifitseerinud. Anton Suurkase ebakorrektsusele pärimuse kogumisel pööras tähelepanu juba Jakob Hurt (1895).

\section{Arhiiviallikad}

E - Matthias Johann Eiseni rahvaluulekogu, 1880-1934 ja mõned varasemad tekstid

ERA - Eesti Rahvaluule Arhiivi rahvaluulekogu, põhiliselt 1927-1944

ERM - Eesti Rahva Muuseumi rahvaluulekogu, 1915-1925

EKS - Eesti Kirjameeste Seltsi rahvaluulekogu, 1867-1891

H - Jakob Hurda rahvaluulekogu, 1860-1906 


\section{Kasutatud kirjandus}

Allen, E. David \& Hatfield, Gabrielle, 2004. Medicinal Plants in Folk Tradition. An Ethnobotany of Britain \& Ireland. Portland: Timber Press.

Eestikeelsete taimenimede andmebaas (Index of Estonian Plant Names) (http:// www.ut.ee/taimenimed/ - 20. juuni 2008).

Eilart, Jaan \& Kask, Maret \& Kuusk, Vilma \& Laasimer, Liivia \& Lellep, Elli \& Puusepp, Visolde \& Talts, Silvia \& Viljasoo, Linda (koost) 1973. Eesti NSV floora V. Eesti NSV Teaduste Akadeemia Zooloogia ja Botaanika Instituut. Tallinn: Valgus.

Ennet, Diether 1990. BI-Lexicon. Heilpflanzen und Drogen. 2. Aufl. Leipzig: Bibliographisches Institut.

Hiiemäe, Mall 2005. Endis-eesti elu-olu aspekt G.Vilbaste väärtushinnangutes. Gustav Vilbaste 120. sünniaastapäevale pühendatud konverents (http://www.folklore.ee/rl/ era/uudis/vilbaste.htm\#hiiemae - 20. juuni 2008).

HERBA. Historistlik Eesti Rahvameditsiini Botaaniline Andmebaas. Tartu: EFI, Eesti Kirjandusmuuseum. (http://www.folklore.ee/herba/ - 20. juuni 2008).

Hurt, Jakob 1893. Kaheksakümne üheksas aruanne Eesti vanavara korjamisest ja keelemurrete uurimisest. Postimees 9. oktoober 1893, nr 200.

Hurt, Jakob 1894. Sajas kolmas aruanne Eesti vanavara korjamisest ja keelemurrete uurimisest. Olevik 15. september 1894, nr 40.

Hurt, Jakob 1895. Sajas seitsmes aruanne Eesti vanavara korjamisest ja keelemurrete uurimisest. Olevik 3. jaanuar 1895, nr 1.

Issako, Lilian 1989. Köögiviljad ja maitsetaimed. Tallinn: Valgus.

Jürgenson, Aivar 2005. Seened kultuuriloos. Tallinn: Argo.

Kalamees, Kuulo 2000. Süstemaatika. Eesti seenestik. Kalamees, Kuulo (toim). CD. EPMÜ Zooloogia ja Botaanika Instituut, lk 8-17.

Kalle, Raivo 2007. Naturaliseerunud ravimtaimed etnobotaanika vaatenurgast. Hariliku katkujuure, hariliku siguri, aedvaagi, aed-mädarõika, hariliku seebilille ja lõhnava kannikese näitel. Mäetagused 36, lk 105-128 (http://www.folklore.ee/tagused/nr36/ kalle.pdf - 20. juuni 2008).

Kask, Kalju 2000. Selts roosteliselaadsed, Uredinales. Eesti seenestik. (Kalamees, Kuulo toim). CD. EPMÜ Zooloogia ja Botaanika Instituut, lk 129-137.

Kukk, Toomas 1999. Eesti taimestik. Vascular Plant Flora of Estonia. Tartu-Tallinn: Teaduste Akadeemia Kirjastus.

Kukk, Toomas jt 2007. Sugukond korvõielised - Asteraceae. Eesti taimede määraja. (2., parandatud ja täiendatud trükk). Leht, Malle (toim). Tartu: Eesti Loodusfoto, lk 262315 .

Kukk, Toomas \& Kull, Tiiu (toim) 2005. Eesti taimede levikuatlas. Atlas of the Estonian Flora. Tartu: EMÜ põllumajandus- ja keskkonnainstituut. 
Kuresoo, Rein \& Relve, Hendrik \& Rohtmets, Indrek 2001. Eesti elusloodus. Kodumaa looduse teejuht. Tallinn: Varrak.

Leht, Malle (toim) 2007. Eesti taimede määraja (2., parandatud ja täiendatud trükk). Tartu: Eesti Loodusfoto.

Lääts, Jaan (koost) 1939. Kodumaa ravimtaimed. Käsiraamat ravimtaimede tundmaoppimiseks ning nende kasutamiseks ravimitena. Viies parandatud ning täiendatud trükk. Tallinn: Kiirtrükk.

Reier, Ülle 2007. Sugukond emajuurelised - Gentianaceae. Sugukond mailaselised Scrophulariaceae. Eesti taimede määraja. (2., parandatud ja täiendatud trükk). Leht, Malle (toim). Tartu: Eesti Loodusfoto, lk 218-219 ja 242-254.

Ostrov, Mihkel 1891a. Palve ja üleskutse üleüldisele Eesti arstirohtude korjamisele. Postimees 6. juuni $1891 \mathrm{nr} 40$.

Ostrov, Mihkel 1891b. Palve ja üleskutse üleüldisele Eesti arstirohtude korjamisele. Olevik 8. aprill $1891 \mathrm{nr} 14$.

Ostrov, Mihkel 1891c. Palve ja üleskutse üleüldisele Eesti arstirohtude korjamisele. Sakala 26. aprill $1891 \mathrm{nr} 17$.

Ostrov, Mihkel 1891d. Esimene aruanne üleüldisest rohtude korjamisest. Olevik 1. juuli $1891 \mathrm{nr} 26$.

Ostrov, Mihkel 1891e. Esimene aruanne Eesti arstirohtude korjamisest. Postimees 2. juuli $1891 \mathrm{nr} 75$.

Ostrov, Mihkel 1891f. Teine aruanne üleüldisest Eesti arstirohtude korjamisest. Olevik 21. oktoober $1891 \mathrm{nr} 42$.

Ostrov, Mihkel 1891g. Teine aruanne üleüldisest Eesti arstirohtude korjamisest. Postimees 29. oktoober $1891 \mathrm{nr} 160$.

Ostrov, Mihkel 1892a. Eesti arstirohtude korjajatele. Postimees 25. aprill $1892 \mathrm{nr} 91$.

Ostrov, Mihkel 1892b. Eesti arstirohtude korjajatele. Olevik 27. aprill 1892 nr 17.

Ostrov, Mihkel 1892c. Eesti arstirohtude korjajatele. Sakala 29. aprill 1892 nr 18.

Ostrov, Mihkel 1892d. Kolmas aruanne Eesti arstirohtude ja arstimise kombete korjamise üle. Postimees 7. november $1892 \mathrm{nr} 252$.

Ostrov, Mihkel 1892e. Kolmas aruanne Eesti arstirohtude ja arstimise kombete korjamise üle. Olevik 16. november $1892 \mathrm{nr} 46$.

Ostrov, Mihkel 1893. Eesti rahwa arstirohtude ja arstimise kombete korjajatele. Olevik 26. aprill $1893 \mathrm{nr} 17$.

Pall, Valdek (toim) 1989. Väike murdesõnastik II. M-Ü. Tallinn: Valgus.

Saukas, Rein 2005. Eesti mõistatuste allikalugu II. Reetor 6. Tartu: Eesti Kirjandusmuuseum. 
Suhonen, Pentti 1936. Suomalaiset kasvinnimet. Annales Botanici Societatis Zoologicae-Botanicae Finnicae Vanamo 7: 1. Helsinki.

Sõukand, Renata 2007a. Kuidas võõras muutub omaks: kaks taime eesti rahvameditsiinis. Mäetagused 36, lk 79-104 (http://www.folklore.ee/tagused/ - 20. juuni 2008).

Sõukand, Renata 2007b. Projekt HERBA: eesti rahvameditsiini ravimtaimede andmebaas Internetis. Paar sammukest XXIII. Eesti Kirjandusmuuseumi aastaraamat. Eesti Kirjandusmuuseumi teaduskirjastus: Tartu, lk 341-348 (http://www.folklore.ee/ rl/pubte/ee/araamat/2007/herba.pdf - 20. juuni 2008).

Tammeorg, Johannes \& Kook, Oskar \& Vilbaste, Gustav 1973. Eesti NSV ravimtaimed. 3., parandatud trükk. Tallinn: Valgus.

Vallner, Rudolf 1929. Eesti rahvarohtude sõnastik: Käsiraamat apteekritele ja arstidele. Tallinn: Raamatu kokkuseadja väljaanne.

Vallner, Rudolf 1913a. Üleskutse arstirohtude nimetuste korjamisele. Kiir 2. märts $1913 \mathrm{nr} 26$.

Vallner, Rudolf 1913b. Üleskutse arstirohtude nimetuste korjamisele. Tallinna Teataja 4. märts $1913 \mathrm{nr} 52$.

Vallner, Rudolf 1913c. Üleskutse arstirohtude nimetuste korjamisele. Päevaleht 24. aprill $1913 \mathrm{nr} 91$.

Vallner, Rudolf 1913d. Üleskutse arstirohtude nimetuste korjamisele. Olevik 1. mai $1913 \mathrm{nr} 32$.

Vallner, Rudolf 1913e. Aruanne arstirohtude nimetuste korjamise üle. Postimees 4. oktoober $1913 \mathrm{nr} 229$.

Vallner, Rudolf 1913f. Aruanne arstirohtude nimetuste korjamise üle. Olevik 9. oktoober $1913 \mathrm{nr} 77$.

Wiedemann, Ferdinand Johann \& Weber, E. 1852. Beschreibung der phanerogamischen Gewächse Esth-, Liv- und Curlands. Reval: Kluge.

Viires, Ants, 2000. Puud ja inimesed. Tartu: Ilmamaa.

Vilbaste, Gustav 1993. Eesti taimenimetused = Nomina vernacula plantarum Estoniae . Eesti Teaduste Akadeemia Emakeele Seltsi toimetised 20. Tallinn: ETA Emakeele Selts.

Vilbaste: Eesti taimenimetuste arvutiregister. Versioon 2.1. Tallinn, Ecolink, 1993. (http://www.loodus.ee/vilbaste/). Allalaaditud 2004 detsember. 


\title{
Summary
}

\section{Relations of Folk Plant Names with the Botanical Nomenclature in Database Herba}

\author{
Raivo Kalle
}

Key words: archive texts, Estonian folk medicine, ethnobotany, database HERBA, Gustav Vilbaste, linking of folk plant names with the botanical nomenclature, folk plant names, phytonyms

HERBA, the Estonian folk medicine database of herbal treatment (available at http://www.folklore.ee/herba), has been the source of lore texts about the use of plants and herbs as popular remedies since 2006. At the present moment, the database includes the earliest archive texts up to the year 1939, estimated to constitute slightly less than half of the total number of texts. The identification of plant names in the texts are largely based on the monograph Eesti taimenimetused ('Estonian Plant Names') by Gustav Vilbaste (1993). Even though most of the collected Estonian plant names have been identified by Vilbaste, new ethnobotanical names emerge while processing the lore material. The article describes the linking of new folk plant names with the botanical nomenclature and establishing connections with the already known folk plant names (on the basis of texts in the database and specialised literature). The database text can be associated with the species on the basis of three criteria: folk plant name (according to Vilbaste's monograph), the Latin name included in the text, and the plant description. The number of informants with more than one Latin extension in the database is currently 11 . Some texts may correspond to nearly all the criteria, but this is an exception rather than a rule. The largest number of Latin names has been contributed by the following informants: pharmacist Hans Jako (in Jakob Hurt files), physician Mihkel Ostrov in 1891 and 1892 (folklore files of the Society of Estonian Literati), school teacher Julius Lunts in 1937 (Estonian Folklore Archives collection) and medical student Jaan Lääts in 1938 (Estonian Folklore Archives collection). Gustav Vilbaste has likewise used the texts of the said informants, though selectively; for instance, the text contributed by Mihkel Ostrov yielded more than 15 new equivalents. The most time-consuming section of the work was to establish connections according to other plant names and/or description and habitat represented in the texts. Usually, a plant can not be identified on the basis of a single text and the results are unreliable. For identification, texts from different collections were gathered together and were analysed according to different parameters, such as the origin of the text, informant's background, other names mentioned in the text and so on; in addition, the results were compared against the data of plant geography. As to the more complicated texts, mycologists and botanists had to be consulted with. One of the aims of the article is to publish the plant names rediscovered in the course of the work and provide inspiration for deriving new Estonian names for species so far unnamed (e.g., family Gymnosporangium). 